\title{
Measuring the Effectiveness of Simulation-Based Education (SBE) in the Performance-Based Design Studio
}

\author{
Khaled Aly Tarabieh, Nouran Magdy El Begermy \\ ${ }^{1}$ The American University in Cairo, Cairo, Egypt
}

\begin{abstract}
Simulation based-education (SBE) is becoming increasingly widespread among architectural design studios worldwide. SBE supports students with an innovative and effective learning environment. Its overall objective is to allow students an experimental environment for design testing, and to enhance the transition of the skills learnt to real life professional practice. The effectiveness of SBE is related to a variety of factors that may be either student or faculty driven, tools and technology driven, curriculum driven (i.e. related to the time of offering or mode of application) or a hybrid of all. To measure the effectiveness in a core course offered half way in the architectural program, a study was conducted to identify the studio learning challenges and accordingly the proper metrics that can be identified to construct future performance indicators for instructors that can quantify the effectiveness of the teaching methods used. Several questionnaires, focus groups sessions, and evidence-based analysis of student work came together to form the research design. The findings validated earlier assumptions in similar previous studies, and recommended the use of a common structure for effective measurement of learning outcomes and teaching methods, with recommendations for future consideration.
\end{abstract}

\section{Introduction}

Building Performance Simulation (BPS) is being used more and more during the development of design proposals for architectural design students in undergraduate programs. Due to the shift in the technological and pedagogical approaches, in addition to the market demands, teaching architectural design for students -typically half way in the architecture programis a process of great complexity, with a set of tools designed for professionals only. Today, integrating sustainability into the architectural design education is more of a market demand and an indicator of success for programs seeking quick placement of their graduates in the job market.

While the job market continues to demand specific capabilities for entry-level architectural graduates, students are required to show evidence of knowledge concerning building energy performance; accordingly, a sound and comprehensive undergraduate training is required. BPS tools are not a product of charts and tools only, but continue to emerge as an evolving tool for design thinking process. Previous studies have discussed new approaches to help with design problem solving (Casakin \& Goldschmidt, 1999), hence improving the complexity of the design solutions through projects that maintain the core of the architecture education. Using BPS tools during the design thinking process gives the design great potential; on the other hand, it does have its challenges and a varied range of limitations (De Wilde, 2017). Several studies have addressed the topic of using BPS tools in the design studio and their suitability for innovation and visualisation. Previous studies offered simulation courses which were based on a method of knowledge transfer than as a dedicated design tool, and the integration of simulation in the architecture curriculum and the challenges facing it (Delbin, 2007). Other studies such as (De Wilde et al., 2002) discussed offering simulation training at the proper time and during early stages of design, and asserted the value it adds to the program. Since designers are solution-led, not problemled (Cross, 2006), it was recommended to have foundation classes using BPS in order to integrate and comprehend the assessment in the design process and to produce relevant design solutions (Pedrini and Szokolay, 2005). In order to evaluate the solutions, the output of the simulation and its proper interpretation must be well understood at the different stages of design. A study addressed the significance of BPS on the form and design (Naboni, 2013), where daylight can be one of the design drivers, (Ibarra and Reinhart, 2013) focused on this aspect of the tools. Of the earlier works published about the topic, a study discussed using unconventional teaching methods, where learning by playing through gaming is used (Reinhart et. al, 2012), the game based approach was the most favourable among students (DeBaillie, 2012 and Tarabieh et al., 2013).However, it did not specifically mention the additional value in comparison to the conventional learning approaches. To advance the teaching method, curriculum restructuring was addressed to give the student the maximum potential to integrate with SBE (Satish, 2014) and the introduction of simulation in the classroom through instruction to both engineering and architectural students (Charles and Thomas, 2009). The issue of the introduction of SBE in architecture education, where it is a continuous cycle of learning and application, was addressed by (Morrison and Hopfe, 2015). It was addressed not only at the early stages of design, where BPS is the main design-guiding tool (Timothy, 2013), but on the full stage as well. Several 
studies on the integration of BPS and its limitations documented the students' utilization of the tools and its implementation during the design development phase, (Biggs, 1996 and Cottrell, 2013) in addition to the limitation of tools and the need for a generation of tools with more friendly interfaces (Soebarto, 2005). Recent studies addressed the possible educational barriers when teaching SBE to students (Hopfe et al., 2017), along with detailed documentation of teaching resources and course structure (Strand et al., 2016). In addition, it touched upon the barrier of the "why" rather than the "how" to use the tools among students (Göçer and Dervishi, 2015 and AlMatarneh and Fethi, 2017). Lastly, a study addressed the curriculum development in light of integrating BPS tools during design process, to maximize the potential of the tool and to fill the gap between the theory and practice with highlighted potential of applying BPS (BeausoleilMorrison, 2019) and additional challenges to the learning method (Hernandez Neto, 2018).

Based on the previous studies, a number of questions shaped the boundary of the discussion as follows:

- Is the adoption of Simulation Based Education (SBE) enough to support the students with an experimental environment for design testing and to improve the transition of the skills learnt to real life professional practice?

- How should the faculty approach the integration of a design dimension within a one-semester undergraduate design studio on BPS?

- How and when should we implement the integration of BPS in undergraduate architecture design education?

\section{Methodology}

The study addressed the integration of Building Performance Simulation within higher education environment -specifically the architectural education environment- to promote Simulation Based Education (SBE). Through a survey-questionnaire, a design studio taught by the instructor was mapped in tool use and student reflections; the chronology of the tools used throughout several years of offering were documented as well. Three surveys were distributed to the students, faculty and alumni of the program. These surveys were compiled, analysed, and used for re-programming the course learning outcomes and student assessment. Thirty students from Design Studio Two (Year 2 in the Program) who passed a prerequisite course in Environmental Controls (Theory) were selected for the study. They participated in a questionnaire-based survey to measure the students' willingness to learn and experiment with the SBE course.

The objective of this study was identifying the challenges and limitations of SBE in architectural education and design process, reaching out to the student community and using the experiences gained in previous studies to structure the survey questions. This is because the effectiveness of SBE is related to a variety of factors that may be student or faculty driven, tools and technology driven, and or curriculum driven (i.e. related to the time of offering or mode of application) or a hybrid of all factors.

\section{Course structure}

The test course focused on using simulations to comprehend the impact of the design on thermal performance, indoor comfort, and energy use. The instructor taught the same class throughout 12 semester offerings (7 years) with different tools wand an almost identical student profile, monitoring the impact of simulation tools on their learning process and professional life of the students.

The length of the course was typically fixed to sixteen weeks, inclusive of final exams with lectures, studio work and tutorial sessions. The lectures addressed the basics and fundamentals of building performance simulation and address with detail-selected tools and programs. The students were required to work on a set of assignments to utilize the tools for initial practice and then apply the learned skills on their studio project while using the tools for development.

\section{Survey Questionnaire}

The research investigation was based on a surveyquestionnaire; some questions were multiple choice, and others were short answers along with statement rating. The respondents were able to add additional information and share their experience and feedback to assist with the future development of SBE. The main objective of the research was to analyze the role and value of simulation tools in a performance-based design studio. Specifically, the study revolved around the use of simulation tools in the design studio among the undergraduate early design courses, graduation design courses and graduates in practice. All the students were directed to learning by doing methodology to individually interact with the tool's functionality using their own design projects at different levels of design development and experiment with the different capabilities of the tools. Due to the students' level and background in building physics and building systems along with their general technical ability to work with the tools, it was understood that not all of them were able to conduct a full simulation exercise. Since the students had varied backgrounds along with their technical abilities, not all of them possessed the skills to conduct a full simulation and to understand the output clearly.

Thirty undergraduate students who passed the main course introducing the tool concepts were selected for the present study. They participated in a detailed questionnaire-based survey to measure the student acceptance of the simulation for design development and to get written student feedback to advance the development and integration of SBE within the curriculum in the future. It is also worth noting that all students surveyed were required to take one environmental controls course which touched on issues of fundamentals and theory; the following term they were required to take a core studio with a theme of sustainability in architectural design. Much of the tools 
learned took place during the latter course. The questionnaire was structured into four sections: background knowledge, application, course outcomes and future considerations.

Section One - Background knowledge: assesses the background of the student in relation to using simulation tools, the duration of exposure to the topic of simulation along with skills. The purpose is to understand the attitude towards the topic of simulation, delving into the learning methodology to measure the level of willingness to learn along with the tools used and to map out the students' skills and familiarity with simulation tools, background knowledge and training.

Section Two - Application: Focused on the application of simulation along with other areas to observe the students' level of expertise and to know whether they were able to relate the information given with other coursework or not.

Section Three - Course Outcomes: reflects the course outcomes of the design studio and the exposure to BPS tools, looking at the student's comprehension of simulation during the design process and the complexity of the tools, and to identify its characteristics and what makes it "Student Friendly". Focus group sessions were conducted and helped to identify the proper metrics and associated KPIs for instructors to quantify the effectiveness of the teaching methods used.

Section Four - Future Considerations: assesses the area of development and future considerations proposing virtual reality as one of the alternatives for future simulation education. The survey focused on the notion of how to integrate SBE within the current curriculum through the assessment of the student response to the limitations and challenges of the tools, thus the target is to:

(a) Observe if SBE provides the students with an innovative and effective learning environment, encouraging the students to develop their designs creatively, allowing experimentation of design alternatives to reach creative architecture solutions, and facilitating the transition of the students to real life professional practice.

(b) Identify the main factors that ensure the effectiveness of SBE are relevant to Student driven factors, faculty driven factors, tools and technology driven factors (i.e. generation of tools with more friendly interfaces), and curriculum driven factors (i.e. Related to the time of offering or mode of application).

(c) Develop a set of metrics that can shape future key performance indicators to ultimately help to quantify the effectiveness of the SBE teaching methods used, addressing the tool popularity during a conventional studio setting (i.e. lectures within class applications) or an unconventional studio setting (i.e. learning by playing through gaming).

(d) Assess if the current offering of Building Performance Simulation Education is adequate to support the required project design quality requested by the Architecture Curriculum and Real Life Professional Practice, evaluating the effectiveness of simulation tools in the design process and final product.

\section{Results}

More than half of the respondents were not familiar with SBE or BPS tools before taking the course $(90 \%)$. The majority $(60 \%)$ had between 0 to 12 months of experience to learn BPS. The duration factors played into the willingness of the students and their capacity to comprehend and apply the basic principles of BPS. The majority $(63.3 \%)$ of the respondents received their first BPS education during a design studio, while $36.6 \%$ received their education in hands-on training and $20 \%$ during a mandatory training session as an application part of a course (Figure 1). The main teaching method was face-to-face teaching, which included lectures and supervised in class-assignments. The survey aimed to identify the appealing factors that attract students to BPS tools, in order to integrate the attractive element in the educational process in an effort to introduce SBE as a continuous learning cycle.

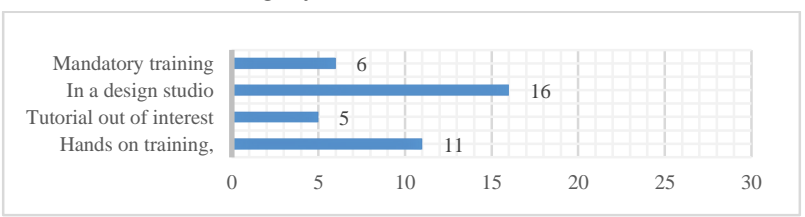

Figure 1: Teaching methods used - multiple selections were possible

The majority of the tools used in studio were REVIT (with Autodesk Insight 360), Climate Consultant, and Ecotect. Sketch-Up (with add-in of Skelion) and Autodesk Vasari were also widely used (Figure 2). A few respondents commented on their preferred tool: they depended on a user-friendly interface, while allowing the chance to explore the impact of the architectural decisions during the design process.

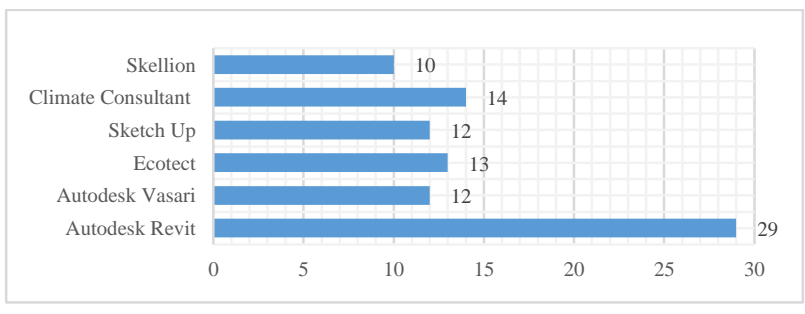

Figure 2: Software programs most commonly used among students - multiple selections were possible

\section{Application}


The survey findings indicate that through experiential learning, a deeper understanding and integration of SBE in the design studio is possible, as indicated by the general interest of the students in the topic. This definitely supports the call for a continuous learning cycle of BPS in continuous and successive design studios. The areas of BPS-taught modules that were of interest to the students are shown in Figure 3. From the respondents, it is apparent that the more friendly and graphical the visualization of the tools are, the higher the interaction of the students with the tool. Eighty four percent of the students utilized REVIT primarily as both a drafting and analysis tool specifically for Daylighting Analysis; eighty percent used it for shading and shadow analysis, and seventy three percent integrated energy simulation in their process of design development.

Figure 3 shows the different applications used and the tendency of the students to deviate the analysis towards the graphical attractiveness of the output charts rather than the purpose of the analysis.

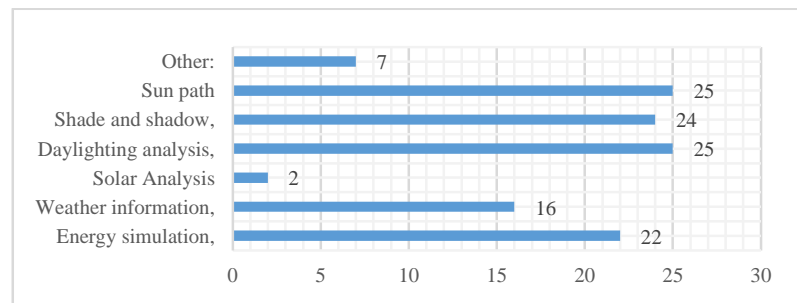

Figure 3: Areas of BPS used among students - multiple selections were possible

The research team identified that time plays a role in the comprehension process and the ability to apply the assessment results on the design. In order to understand the impact, we asked if SBE tools were offered at an adequate stage during design, sixty percent of the respondents replied that they weren't, while forty percent replied that their BPS education was at an adequate stage.

The majority of the respondents $(66.7 \%)$ applied their SBE education during the schematic stage of the design, while ten percent applied it during development stage and $23.3 \%$ applied it during conceptual phase. On the other hand, it was observed that despite the design limitations during the conceptual phase due to the simulation results, the final designs were more responsible, functional and justifiable. This attested that a need for an integrated BPS exposure was best at a much earlier design stage. Forty seven percent of the respondents reported that they understood the assessment, but were unable to apply it on their design, due to comprehension and data interoperation obstacles.

To identify the challenges arising from technology change, we asked the respondents if SBE tools validated or discouraged their design, seventy percent reported that it validated the design, but on the other hand, only sixty percent were able to apply the assessment results on their designs. The correlation between the time of application and level of satisfaction and comprehension of the BPS principles were identified. Those who were able to comprehend the concepts altered their designs to a degree that did not affect the original concept of their building design. Figure 4 demonstrates the most common sources of discouragement during assessment.

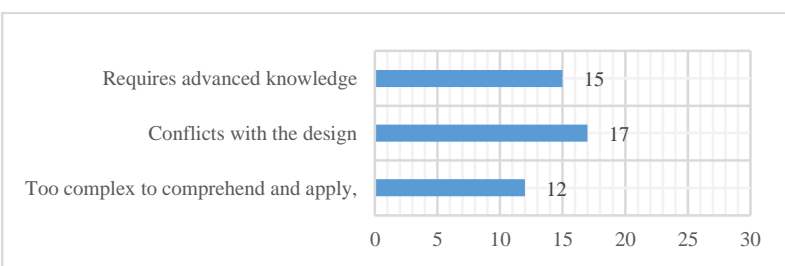

Figure 4: Difficulties mentioned by the students when using SBE tools

There were misconceptions identified among the students on the difference between "running a successful simulation" and "interpretation of the output data". Students faced many challenges in the interpretation of the output data, $56.7 \%$ reported that it conflicted with the design, while fifty percent reported that it requires advanced knowledge and forty percent of the respondents reported that it was due to the tool complexity. This question allowed for three main research observations: the main target user of the SBE tools, the impact of SBE tools on creativity in design and the difficulties with data interpretations.

Observation 1: the tools were not made for educational purposes, but for professional ones. $83.3 \%$ of the respondents confirmed their awareness that the tools utilized are for professional use, $93.3 \%$ reported that they would use a more simplified version of the tools utilized. $56.7 \%$ reported that REVIT (most preferred tool among students) was not properly utilized. When asked to provide their insights, the respondents reported that it was used as conceptual tool without putting into too much consideration for how projects would be accurately built. The most common response was on the need for a balanced teaching method between traditional and performance-based driven studio objectives and to support the transition of the studio to be a more interactive hands-on environment.

Observation 2: SBE tools conflict with the design process in the typical design studio. For the questions on limiting of creativity, surprisingly, only $20 \%$ reported 'Yes', while $40 \%$ reported 'No' and 40\% 'Maybe'. This may indicate confusion or misunderstanding of the role of SBE tools during the design process. $80 \%$ of the respondents confirmed that running simulation of the design proposals signifies "the end" of the design process. This indicates some of the misconceptions, which was not comprehended earlier explaining simulation as a 'process' not as an 'end result'.

\section{Course Outcomes}

The students need to be able to grasp the importance of their design decisions by being able to investigate the impact of such decisions on their designs in different 
performance criteria, moreover, be able to make links between the values (numerical) required for the simulation and the architectural solutions. Accordingly, the research team wanted to measure the awareness of the respondents on the importance of SBE tools, so we asked if the BPS tools played an integral role in advancing the design. $86.7 \%$ of the respondents confirmed the importance of BPS tools during their design process, but the respondents did comment on how they would like to have SBE as part of their design and studio culture, because they only use BPS tools when asked to. In an attempt to focus the "why" not the "how", we asked the respondents if they were able to grasp the effectiveness of the assignments to identify how and where was simulation easy enough for the students to comprehend, where it was serving the student not the process of simulation itself. $40 \%$ of the respondents acknowledged the importance of the daylighting assignment, while $43 \%$ agree with the efficiency of the tool. On the other hand, Energy simulation on REVIT was the least utilized tool with $9 \%$, reflecting back on how the input data and the interface play an important factor in the comprehension process. Figure 5 shows the respondents' perceptions towards different BPS tools.

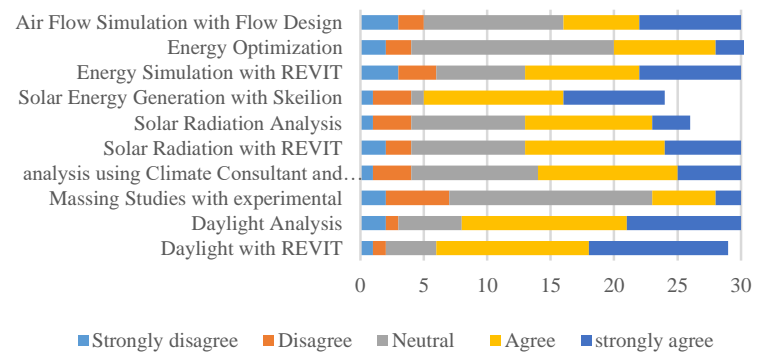

Figure 5: Effectiveness of the BPS Modules among Students

\section{Design Studio Future Development}

Figure 6, demonstrates the different teaching methods in question. The shift in the studio teaching towards a more unconventional teaching method, where a conventional approach (i.e. lectures with in class applications) and an unconventional approach (i.e. learning by playing through gaming). The majority of the respondents (96.7) were leaning towards a more unconventional learning method.

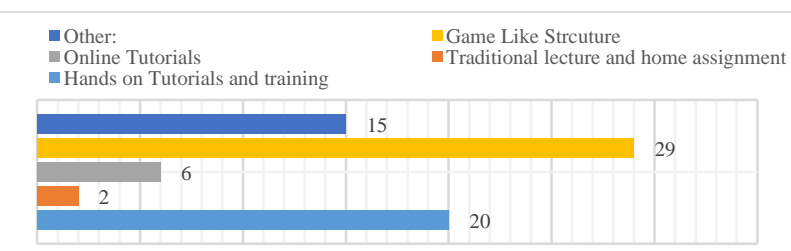

Figure 6: Preferred Learning Methodologies to promote SBE multiple selections were possible

The respondents have acknowledged the importance of BPS tools and the potential of having an SBE mindset, but if offered in a less formal method during the early design studios. They recommended that SBE to be introduced early in every design studio to allow time for analysis and optimization. 74\% reported that they would consider BPS as a conceptual design-guidance tool upon the restructuring of the simulation offering methods. The respondents have expressed their willingness to learn, but also that they needed less formal teaching methods, especially during early design stages where they can apply what they learned, rather than have to practice with the tool alone.

\section{Discussion}

To evaluate the utilization of environmental simulation tools and their integration in the typical undergraduate education and its effectiveness, the research team was able to identify, using the surveys, a group of metrics and indicators for goal assessment and measurement of the learning outcomes. These indicators are:

- Appropriateness/Suitability of the learning environment

- $\quad$ Student intent to use BPS as a design guide

- User friendly interface and impact on usability

- Data volume required for simulation and ease of interpretation

- Ability to provide a flexible/unconventional continuous learning approach

- $\quad$ Complexity of the tool and ease of comprehension

\section{Future Suggestions}

\section{BPS to be a Continuous Cycle of SBE}

The research team was aware that students were not utilizing the full potential of the tool because they were not exposed to the full Building Information Modeling (BIM) functionality of the commonly used tool. While REVIT is the most used among students, it remains complex and not fully comprehended both for those who seek results or assessment. The students suggested using a simplified tool because they wished to integrate BPS results and optimize their designs. It was discussed that the current education offering is not adequate to support the real life professional practice; as a result, a gap between the real job market (practice) and the educational platform (learning and research) exists. Accordingly, with these findings, it was suggested to continuously survey the program graduates to measure the validity of these findings. Furthermore, it was suggested to monitor the students' comprehension through continuous improvement of design, and to encourage the development of alternative solutions to maintain the quality of a design, develop new and innovative ideas and consistent use of BPS throughout all phases of design process to maintain the desired continuous learning cycle. It was mentioned that BPS would be more desirable if the students were able to get accustomed to utilizing the tools during design studio in earlier stages -from Year 1, for example- in order to learn a solid foundation on the fundamental knowledge and skill set needed to conduct a successful performance based studio-utilizing BPS.

Accordingly, BPS should:

- $\quad$ Be the design decision driver.

- Be the main structure of the design problem 
- Improve the decision making process, making it easier to comprehend the impact of any architectural decision.

- Make students more aware of the implications of their architectural decisions on the performance.

\section{More of a Program Culture rather than a Dedicated Studio}

SBE supports students in an innovative and effective learning environment; its overall objective is to allow the students an experimental environment for design testing and to enhance the transition of the skills learnt to real life professional practice. Looking more into the impact of SBE on the courses that follow, it was decided to question the impact of the prerequisite courses and to apply building performance simulation and the need to expand the curriculum to include more courses relevant to building physics in lieu of just introducing the fundamentals only, where it expands beyond one semester. BPS should be more of a culture rather than a studio, and should start to be more ubiquitous throughout the rest of the coursework so that it becomes more of an integral part that interacts with the design process rather than being an option. The overall initiative is to have BPS as a coherent element in the design process. Suggestions were made to enhance the educational process and exposure mechanism to BPS tools to the students through the integration of information in the earlier years of the program. One suggestion was to link the design projects with practice allowing actual clients to be part of the studio jury as well as design professionals.

\section{A Continuous Process of Course Development}

Utilizing the outcomes of the focus groups and the survey questionnaires, the structured development of the course over the span of seven years, with the implementation of the student feedback and the simulation tools used at every mapped out stage. The course ran through fourteen offerings, where there was the challenge of learning different tools to expose the student to a variety of simulations to be integrated in the design. The tools changed over the span of the course development due to the fast-pace changes in the technology platforms used to support SBE. Using energy simulation in student design projects is becoming a robust task as generations of tools, like REVIT, are starting to be associated with a more friendly interface and the analysis mainly performed in the cloud; however, a consistent issue persists on the quality of input data used and the coherence of the output data.

The amount of time spent between teaching theory, application and analysis needs further thinking to address the method of comprehension and development of BPS concepts among the students.

\section{Recommendation for a Student Based Simulation Tool}

The study indicates that the current tools on the market are created for the sole purpose of commercial/professional use, and therefore are too complex for the typical student to comprehend. The choice of tool depends on its accuracy, flexibility (interoperability with other applications and the ease of use to develop architectural models), duration of analysis and ease of data interpretation, geometry inputs (ease to simulate complex designs), and the user interface. As a result, a tool that offers design exploration coupled with simplified level of analysis is needed to assess the impact of the architectural decisions. The tools could develop simplified metrics and indicators for the students to be able to comprehend the complex notion of the numerical data input/output as they work towards a common goal or objective.

Due to the wide variation among the different tools that support BPS environment, students are not able to get accustomed to the process of using BPS during the design process if they get exposed to different tools during a short duration. As a result, the students do get to use the programs and comprehend the impacts on the design, but the question is if they understand the concept of BPS. Moreover, not all students take the results to the application process, which means that they do not perceive BPS as an integrated design development tool. Architectural programs could seek to develop the issues of design development through the integration of BPS tools with the design thinking process.

To ensure that the students are more involved and engaged with the application of simulation, the guidelines for what the tool be characterized by are to be highly graphical, does not require complex numerical input that would produce a clear model with expert knowledge to navigate through. Students need to have a solid background knowledge in building physics and systems design before using simulation tools or risk having difficulties in the comprehension of data due to lack of proper skills and knowledge base. It is also recommended to have a co-instructor in the course with strong background in building systems to act as a Mechanical/Electrical/Plumbing (MEP) advisor to help the students in the proper interpretation of the output data and accordingly for the suggested design changes.

The current limitations were acknowledged as the lack of emphasis of the importance of SBE, along with the need to develop a software the is user friendly to the students, where they can comprehend the simulation results through a simpler and less complex simulation tool. This would increase the student willingness to experiment. Other limitations include time-consuming nature of the professional and complex tools, where the students do not know whether to focus on the design or the skill to manage the tool. Finally, there is a need for horizontal and vertical coordination between different courses that can take SBE into consideration as one of the main objectives of the program as a whole.

\section{Conclusion}


This research utilizes an actual course as the case study; a sample of thirty students responded to a structured survey questionnaire along with focus group discussions and one-on-one discussions. We understand the study is local so the course in question and the data should not be generalize the wider community of BPS users. However, we believe that the current tools shared across many programs worldwide and available for students are still complex and may cause a learning problem as it requires specific skill and preparation for the quality of data input/ output explanation. The study is comprised of the total number of the students involved in one of the course offerings. Acknowledging this bias, future scaling of this research for the software development stage should engage a larger audience to properly report and generalize the research study outputs. The research aimed to address misconceptions on the timing of conducting a simulation in the course, along with the purpose and ability of output data interpretation. The objective of developing the curricula should continue to revolve around teaching the students to be producers of architectural design rather than producers of simulation models; however, the performance-based aspect of these designs cannot be assessed except with simulation tools. Lastly, the study outcomes help as guidelines to develop an adaptive course curriculum that can allow for a balanced approach between creativity and performative teaching environments.

In conclusion, we strongly suggest a closer look at the available tools for students and how we prepare these students for the professional market, particularly as it relates to the understanding of the performance gaps in the understanding of the generated output and whether it is understood well at the different levels. As the rate of students willing to integrate BPS tools in their design process has increased and shows potential, the risk of misinterpretation of results still remains. Additionally, at some point the nature of data produced -which is not fully coherent yet- is trusted because it is commercialized as a validated tool. We are seeking to educate BPS users rather than producers. The study vouches for a student oriented tool, to produce a generation of aspiring architects with experience in interdisciplinary studio work involving BPS, where they have received support with data interoperation and prior knowledge in principles of simulation. Should the students understand uncertainty and data challenges, the algorithm "engine" of the tool used? Is SBE a proper method of learning for undergraduate design studio? Are we moving in the direction of restriction of BPS tools and allowing it for the advanced level analysis only "graduation project level" and professional use, thus, prohibiting the use of it for the remainder of the undergraduate education? The previous questions require further investigation and research to better equip students with means of good interpretation of data, design user friendly and easy to comprehend tools, and establish a good understanding of the tool in lieu of the common use of completing the requirements with coloured charts that fill the analysis gap.

\section{References}

Al-Matarneh, R., \& Fethi, I. (2017). Assessing the Impact of CAAD Design Tool on Architectural Design Education. Malaysian Online Journal of Educational Technology, 5(1), 1-20.

Beausoleil-Morrison, I. (2019). Learning the fundamentals of building performance simulation through an experiential teaching approach. Journal of Building Performance Simulation, 12(3), 308-325.

Biggs, J. (1996). Enhancing teaching through constructive alignment. Higher education, 32(3), 347-364.

Casakin, H., \& Goldschmidt, G. (1999). Expertise and the use of visual analogy: implications for design education. Design studies, 20(2), 153-175.

Charles, P., \& Thomas, C. (2009). Building performance simulation in undergraduate multidisciplinary education: Learning from an architecture and engineering collaboration. In Proceedings of Building Simulation.

Cottrell, S. (2013). Revolution by stealth: The impact of learning development on democratising intelligence through constructive approaches to student support. Journal of Learning Development in Higher Education, (6).

Cross, N. (2006). Design as a discipline. Designerly Ways of Knowing, 95-103.

DeBaillie, L. (2012). Teaching Commercial Building Energy Dynamics through Simplified Energy Modeling Tools. The American Council for Energy Efficient Economy (ACEEE) Summer Study on Energy Efficiency in Buildings.

Delbin, S., da Silva, V. G., Kowaltowski, D. C., \& Labaki, L. C. (2006). Implementing building energy simulation into the design process: a teaching experience in Brazil. In IN: proceedings of PLEA2006, the 23rd Conference on Passive and Low Energy Architecture. Proceedings. Geneva, Switzerland (pp. 755-761).

Delbin, S., da Silva, G. G., \& Kowaltowski, D. (2007). Teaching for integration of building energy simulation in the design process. In Proceedings of the $2^{\text {nd }}$ PALENC Conference and 28 th AIVC Conference on Building Low Energy Cooling and Advanced Ventilation Technologies in the (Vol. 21, pp. 27-29).

Göçer, Ö., \& Dervishi, E. (2015). The use of building performance simulation tools in undergraduate program course training. In Proceedings of BS2015: 14th Conference of International Building Performance Simulation Association.

Hopfe, C., Soebarto, V., Crawley, D. and Rawal, R., (2017). Understanding The Differences Of Integrating Building Performance Simulation In The Architectural Education System. In Proceedings of the 
15th IBPSA Conference San Francisco 2017, CA, USA, 7-9 Aug. 2017.

Ibarra, D., \& Reinhart, C. F. (2013). Teaching daylight simulations-improving modeling workflows for simulation novices. In Proceedings of 13th conference of international building performance simulation association (BS2013) (pp. 1127-1135).

Milne, M., Liggett, R., Benson, A., \& Bhattacharya, Y. (2009). Climate Consultant 4.0 develops design guidelines for each unique climate. In American Solar Energy Society Meeting.

Morrison, I. and Hopfe, C. , (2015). Teaching Building Performance Simulation through a Continuous Learning Cycle. InProceedings of BS2015 14th Conference of International Building Performance Simulation Association 2015, Hyderabad, India, 7-9 Dec. 2015.

Naboni, E. (2013). Environmental Simulation Tools in Architectural Practice. The impact on processes, methods and design. In Proceedings of the PLEA2013 - 29th Conference, Sustainable Architecture for a Renewable Future. Munich, Germany 10-12 September 2013.

Hernandez Neto, A. (2018). Teaching building performance simulation: Considerations on methodologies and course levels. International Journal of Mechanical Engineering Education, 0306419018775596.

Pedrini, A., \& Szokolay, S. (2005). The architects approach to the project of energy efficient office buildings in warm climate and the importance of design methods. In Building Simulation (pp. 937944).

Reinhart, C. F., Dogan, T., Ibarra, D., \& Samuelson, H. W. (2012). Learning by playing-teaching energy simulation as a game. Journal of Building Performance Simulation, 5(6), 359-368.

Satish, B. (2014). The relation between the learning development theories and the Architectural Technology and the Environment programme in PGCAP, Learning Development, Plymouth University.

Soebarto, V. (2005). Teaching an energy simulation program in an architecture school: lessons learned. In Proceedings of the Ninth International IBPSA Conference (pp. 15-18).

Strand, R., Liesen, R., \& Witte, M. (2016). Resources for teaching building energy simulation. Proceedings of SimBuild, 1(1).

Tarabieh, K. et al. (2013), Teaching Energy Simulation in the Architectural Design Studio: An Experimental Approach. In Proceedings of the IBPSA 2013 Building Simulation Cairo. Towards Sustainable \& Green Built Environment. Cairo, 23-24 June 2013.

Timothy, L., (2013). Conceptual Energy Modelling For Architecture, Planning And Design: Impact Of Using Building Performance Simulation In Early Design Stages. In Proceedings of the International Building Performance Simulation Association. Chambéry, France, 26-28, August 2013. University of NebraskaLincoln.

De Wilde, P., Augenbroe, G., \& Van Der Voorden, M. (2002). Managing the selection of energy saving features in building design. Engineering, Construction and Architectural Management, 9(3), 192-208.

De Wilde, P., (2017). The concept of building performance in building performance simulation - a critical review. In Proceedings of the 15th IBPSA Conference San Francisco 2017, CA, USA, 7-9 Aug. 2017. 